\title{
STUDY OF TRIBOLOGICAL PROPERTIES OF SLIDING SURFACES FOR PRODUCTION AND PACKAGING LINES
}

\author{
Vladislavs Butkevics, Daina Kanaska \\ Latvia University of Life Sciences and Technologies, Latvia \\ kk99@inbox.lv, daina.kanaska@1lu.lv
}

\begin{abstract}
During production and packaging of various bulk products, the work surfaces of the equipment and their assemblies interact with sliding bodies, and different types of forces are created between them: friction, normal reactions and Van der Waals forces. When packing sliding bodies of different shapes, their parameters, surface roughness, mass, as well as the amount of static electricity, microclimate parameters in the room have a more significant impact on the movement of sliding bodies and the spreading rate in the packing area of the dosing equipment. When designing dosing equipment, it is important to know the sliding friction coefficients for different contact materials in order to optimally select the parameters of these materials and the sliding surface angle. The aim of the study is to select an appropriate method of experimental research to determine the dependence of the coefficient of sliding friction on sliding bodies on their geometrical parameters, mass and physical properties. The study was performed with the materials used for sliding surfaces: thermoplastic polyvinyl chloride film (PVC); stainless steel AISI 316 plate, (without surface treatment) and polished. The experiment was performed by changing the relative humidity values in the room from $30 \%$ to $60 \%$. As a result of the study, it was found that the optimal conditions for the studied materials to slip are at a relative humidity of $30 \%$, the average value of the static friction coefficient is 0.26 and the average value of the sliding friction coefficient is 0.25 . The values of the sliding surface roughness significantly affect the static and sliding friction coefficients, the sliding surface with a roughness of $0.100 \mu \mathrm{m}$ ensures the best slipperiness of the studied sliding bodies.
\end{abstract}

Keywords: dosing, sliding, friction, coefficient, tribology.

\section{Introduction}

In the food, pharmaceutical, agricultural and other industries, in connection with the packaging of finished products on universal and specialized packaging machines, engineers and technologists often face problems related to insufficient research of tribological properties, geometrical parameters and physical properties of the product and the impact of the microclimate of the working environment on the process, which, in turn, reduces the productivity of the equipment and increases the proportion of defective products [1]. In the dosing unit, the sliding bodies move along the sliding plane to the packing zone. The nature of sliding bodies movement is influenced by many external case factors: mechanical interaction between the sliding bodies and the sliding surface, microclimatic conditions, vibrations, the difference in the sliding bodies surface texture. In this case, the spatial orientation of the sliding bodies on the sliding surface, the speed of falling on the packing line and the accelerations resulting from contact with the rotating mechanisms of the dosing unit (e.g., rotating paddles, roller brushes) change $[2 ; 3]$.

If the speed $v$ of the sliding bodies is moved too fast on the packing line, they hit the working mechanisms of the dosing unit, which, in turn, causes damage to the product [4]. The spatial dispersion of the sliding bodies must not cause them to leave the packing line, due to which the parameters of the movement of the sliding bodies (speed and acceleration) are important parameters to ensure the quality of the packing process [5]. The most common damage is related to changes in the shape and physical properties of the sliding body surfaces: chips, fractures, damage to the product surfaces. Products must meet strict chemical, physical and biological properties and damaged products must not be passed on to the consumer [6-8].

During packaging the working surfaces of the equipment and their assemblies interact with the sliding bodies and various types of forces are created between them: friction, normal reactions and Van der Waals forces, or forces of atoms and molecular bonds. Geometrical parameters of sliding bodies, surface roughness, mass, as well as the amount of static electricity, microclimate parameters in the room significantly affect the movement of sliding bodies and the spreading rate in the packing area of the dosing unit [6;9]. The mechanical interaction of friction pairs is described as the result of elastic and plastic deformations in their contact microplanes and the shift of irregularities that occur on the body contact surface (surface layer topography). Van der Waals forces are described by the molecular theory 
of friction. They are based on the assumption that these forces arise due to changes in the degree of molecular interaction of the molecules or atoms in the researched pairs of interacting bodies [10].

The accuracy of friction coefficient values is important in friction force modeling, in the development of antifriction coatings for new materials, and in the development of new friction test methods. The literature has limited information on the values of friction coefficients for specific material combinations and they need to be determined experimentally [11]. It is also necessary to know the exact values of sliding and static friction coefficients for equipment designers to choose the most suitable material and surface treatment [12].

It is known that the values of static $\mu_{s}$ and sliding friction coefficients $\mu_{\text {slide }}$ are affected by the roughness of the contact surfaces of both bodies, body material, oxides and other films on surfaces, sliding speed, vibration, room microclimate parameters (relative humidity, temperature) and, to a less extent, also the nominal contact square of bodies [3; 13].

There are many technical solutions for experimental determination of static and sliding friction coefficients. Let us consider more widely used tribometer devices, which are specially designed to determine the values of these coefficients. The tribotester used to simulate friction and wear at the surface contact in relative motion under controlled conditions [14] is not suitable for studying the movement of sliding bodies on inclined surfaces.

To determine the coefficients of sliding and static friction for solid bodies, a strain gauge method is used, using tensor resistor (force) sensors with data loggers. The basis of this method is to determine the amount of force required to move the body under study from a place on a horizontal sliding surface and to determine the value of the force at which the body slides [15], which is also not suitable for the conditions of the research, because the dimensions and mass of the studied sliding bodies are insufficient, and the structure of the sliding body material also has low mechanical hardness.

In the laboratory, the inclined plane method is often used, which is based on reading the value of the angle $\alpha$ between the slip plane and horizontally to determine the static friction coefficients [3]. This method is suitable for determining the values of approximate static friction coefficients for sliding bodies with different masses and dimensions, but it is not possible to determine the sliding friction coefficients with this method.

The aim of the research is to create a measuring device and to experimentally determine the values of static and sliding friction coefficients depending on the parameters of the sliding surface and sliding bodies and the relative humidity in the environment.

\section{Materials and methods}

For the purpose of experimental research in order to determine the static and sliding friction coefficients for various sliding surface materials and sliding body parameters a tribometer equipment based on the inclined plane method was developed.

In order to substantiate the design of the tribometer, it was necessary to study the force vector schemes acting on the slide body while it is on the sliding plane. According to the force vector scheme in Fig. 1, which acts on the sliding body, which is located on the slope angle $\beta$ of the sliding plane, the body moved out of place and began to slide with a uniform acceleration along the sliding plane.

Taking into account the schemes of operating force vectors and tribological regularities, the construction of a tribometer needs to ensure: determination of the critical slope angle $\alpha$ for the slide body; determination of the sliding angle $\beta$; sliding time $t$ reference system for the slide body; to ensure a constant speed of lifting the sliding plane and smooth movement.

Based on the methods discussed above and the studied force vector scheme, a special tribometer construction was created for the research, see Fig. 2. The developed construction is intended for experimental determination of the starting sliding angle $\alpha$ of the slide body, slide body sliding time $t$ and the sliding angle $\beta$. The construction of the tribometer has no analogous measuring devices, its main advantage is determination of static and sliding friction coefficients by the inclined plane method, operating in automatic mode with data storage function and data export to a data processing program such as MS Excel. 


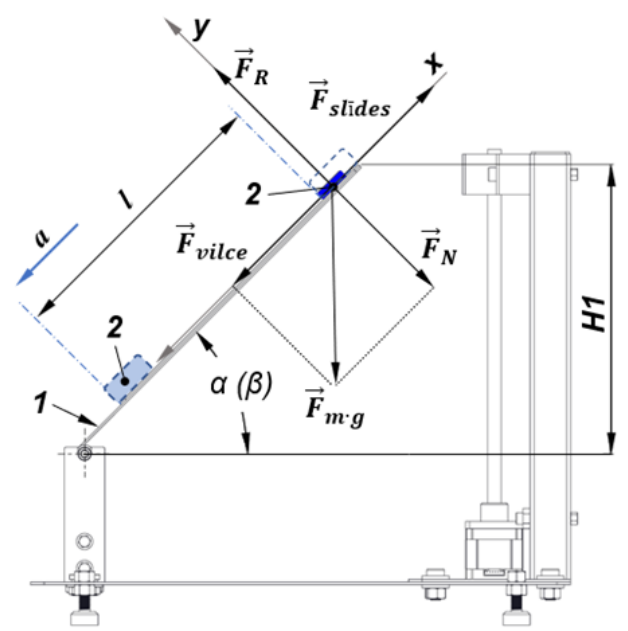

Fig. 1. Force vector scheme: 1 - sliding plane; 2 - slide body; $\alpha$ - static friction angle; $\beta$ - sliding friction angle; $\vec{F}_{N}$ - normal force (downforce); $\vec{F}_{R}$ - support reaction force; $\vec{F}_{\text {vilce }}$ - traction force; $\vec{F}_{\text {slides }}$ - sliding friction force; $\vec{F}_{m g}$ - gravity force; $H_{l}$ - elevated height of sliding plane

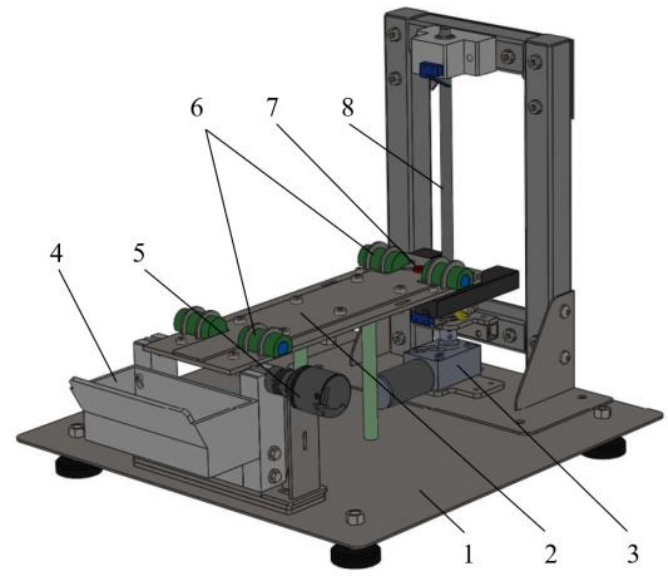

Fig. 2. Tribometer equipment overview: 1 - base with adjustable supports; 2 - sliding plane;

3 - electromotor; 4 - sliding bodies collection container; 5 - angle sensor; 6 - optical pair sensors; 7 - slide body; 8 - sliding plane lifting screw

The construction of the tribometer was created taking into account the geometrical parameters of the investigated sliding bodies, their mass and mechanical hardness, as well as other experimental conditions.

The tribometer (see Fig. 2.) is equipped with optical pair sensors (6) and an angle sensor (5) ensuring high measurement accuracy, while a programmable logic controller (PLC) ensures correct operation of the measuring device. For this tribometer device it is possible to install sliding planes (2) with different roughness. The possibility of achieving a constant lifting speed of the sliding plane is ensured by setting the speed of the electromotor (3).

The accuracy of the measuring device depends on the lifting speed of the sliding plane, including that too high speed can cause a dynamic effect on the sliding body, the resulting static and sliding friction angles will be determined incorrectly. The lifting speed of the sliding plane must be maintained at up to 5 degrees/minute, so as not to cause incorrect movement of the slide body. Thus, the lifting speed must be such that the magnitudes of the forces acting on the slide body gradually change their magnitude, the slower the lifting occurs, the more gradual the intermolecular bond shifts occur, the more accurately the static and sliding angle values will be determined [3]. The configuration of the lifting screw (8) ensures even lifting and lowering starting position of the sliding plane. The installation of the studied slide body (7) on the sliding plane takes place according to a special template, which ensures that the slide body 
occupies the correct starting position before the optical sensors, thus reducing possible inaccuracies in determining the static $\alpha$ and sliding $\beta$ angles, and sliding time $t$.

Static friction coefficients $\mu_{s}$ and sliding friction coefficients $\mu_{\text {slide }}$ are calculated according to formula $(1,2)$.

The coefficient of static friction $\mu s$ is equal to the tangent of the angle of inclination of the sliding plane [10].

$$
\mu_{s}=\operatorname{tg} \alpha,
$$

where $\operatorname{tg} \alpha$-sliding plane tangent of the angle of slope $\alpha$.

The coefficient of sliding friction $\mu_{\text {slide }}$ describes the friction between bodies that are in motion relative to each other [16]. The coefficient of sliding friction is calculated according to formula [12]:

$$
\mu_{\text {slide }}=\operatorname{tg} \beta-\frac{2 l}{g t^{2} \cos \beta},
$$

where $\beta$ - angle of inclined plane;

$l$ - slide body sliding distance to stop, $\mathrm{m}$;

$g$ - acceleration of free fall, $\mathrm{m} \cdot \mathrm{s}^{-2}$;

$t$ - slide body sliding time, $\mathrm{s}$.

The physical and geometrical parameters of the sliding bodies are summarized in Table 1.

Physical and geometrical parameters of sliding bodies

Table 1

\begin{tabular}{|l|c|c|c|}
\hline \multicolumn{1}{|c|}{ Structure and description } & $\begin{array}{c}\text { Surface area S, } \\
\text { mm }^{\mathbf{2}}\end{array}$ & $\begin{array}{c}\text { Nominal } \\
\text { mass, mg }\end{array}$ & $\begin{array}{c}\text { Quantity, } \\
\text { pcs. }\end{array}$ \\
\hline In compressed form, without coating & 71.85 & $500 \pm 3.0 \%$ & 61 \\
\hline In compressed form, without coating & 32.15 & $240 \pm 3.0 \%$ & 61 \\
\hline In compressed form, with polymer coating & 0.66 & $597 \pm 5.0 \%$ & 61 \\
\hline
\end{tabular}

Stainless steel grade 316 was chosen as the sliding plane material with the surface parameters $R a=0.030 \pm 0.001 \mu \mathrm{m}(R z=0.200 \pm 0.009 \mu \mathrm{m}) ; R a=0.110 \pm 0.004 \mu \mathrm{m}(R z=0.892 \pm 0.058 \mu \mathrm{m}) ;$ $R a=0.520 \pm 0.003 \mu \mathrm{m} \quad(R z=4.418 \pm 0.088 \mu \mathrm{m}) ;$ polyvinyl chloride film (PVC) with $R a=0.074 \pm 0.007 \mu \mathrm{m}(R z=0.492 \pm 0.017 \mu \mathrm{m})$.

The experiments were performed under laboratory conditions with controlled room microclimate parameters: relative humidity was regulated from $30 \% \mathrm{rH}$ to $60 \% \mathrm{rH}$ in steps of $10 \% \mathrm{rH} \pm 2.5 \% \mathrm{rH}$; with the temperature remaining constant, $20^{\circ} \mathrm{C} \pm 0.4^{\circ} \mathrm{C}$.

All body parameters are measured with the equipment Checkmaster 4.1, sliding body parameters were automatically compared with the values set in the specification to select only valid sliding bodies.

The roughness of each plate was determined with a calibrated profilometer Mitutoyo SURFTEST $S J-210$, data were compiled in MS Excel computer program, mean values and measurement error were calculated using Student's distribution methodology. The reliability of the experimental data is $95 \%$.

From the experimentally obtained data of the static angle $\alpha$, sliding angle $\beta$ and the sliding time $t$, sliding $\mu_{\text {slide }}$ and static friction $\mu_{s}$ coefficients were calculated in MS Excel computer program. As the amount of data in each measurement reached 61, the chosen data processing method is descriptive statistics (Descriptive Statistics) with coefficient of variation, calculated means, standard error and standard deviation. The reliability of the experimental data is 95\% [17].

\section{Results and discussion}

The dependence of the values of the coefficient of sliding friction $\mu_{\text {slide }}$ on the roughness $R a$ is shown in Figure 3. It can be seen that the value of the coefficient of sliding friction depends on the roughness of the sliding surface in each group of sliding bodies - this is not a random result. For sliding bodies with a flat and spherical surface, the results differ significantly at the smallest and higher values of the sliding surface roughness. 


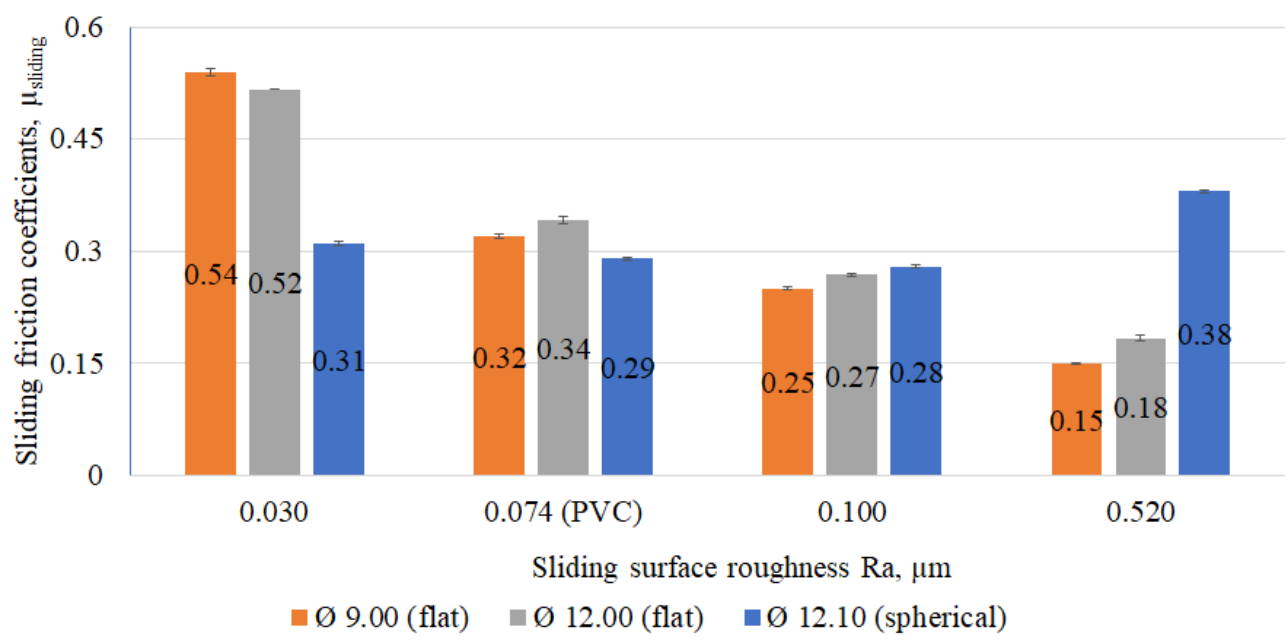

Fig. 3. Sliding friction coefficient $\boldsymbol{\mu}_{\text {slide }}$ values for each sliding body type on sliding planes with different surface roughness

Sliding body size and weight do not significantly affect the nature of this relationship, which is in good agreement with the classical dry friction theory [18]. Flat sliding bodies have a tendency for a significant increase in the coefficient of friction from 0.25-0.27 to 0.52-0.54 (almost twice) with a decrease in the roughness of the sliding plane from 0.100 to $0.030 \mu \mathrm{m}$. Theoretically, the sliding friction coefficients should be lower at a lower sliding surface roughness value, however, there are exceptions in some cases. This phenomenon can be explained by the increase in the actual contact area, the area determined by the number of micro-roughnesses of the two contacting bodies and their areas in direct contact with each other at the micro level [19].

In order to achieve the smoothest possible (laminar) body sliding, the optimal plane roughness is $0.100 \mu \mathrm{m}$. Therefore, it is possible to recommend the use of such material in packaging mechanisms, which will allow fairly even distribution of the product in the package and improve the quality of the packaging process.

The values of the sliding friction coefficients $\mu_{\text {slide }}$ for one type of the slide body at different values of relative humidity of the room and different roughnesses of the sliding plate materials are shown in Figure 4.

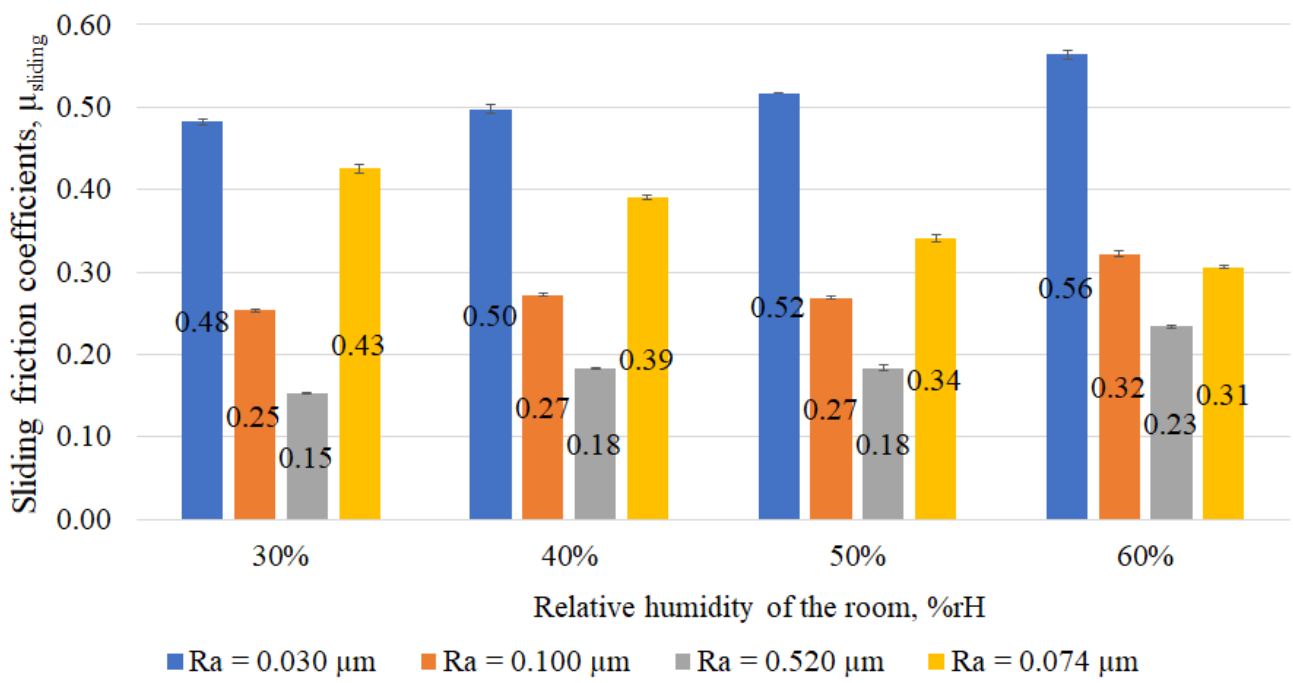

Fig. 4. Values of sliding friction coefficients $\mu_{\text {slide }}$ for one type of slide body on sliding planes with different surface roughness at $30 \%, 40 \%, 50 \%, 60 \%$ relative humidity

In three cases, for stainless steel sliding planes, regardless of their roughness, the absolute increase of the sliding friction coefficient is $0.07-0.08$ with an increase of relative humidity from $30 \%$ to $60 \%$, 
the coefficient increases almost in proportion to the percentage of moisture. As in the first case, the coefficient of sliding friction decreases almost evenly with increasing roughness of the metal sliding surface. This phenomenon can be explained by the fact that certain protrusions on the sliding surface lead to reduction in the friction area between the slide body and the sliding surface. It has been found that increase in moisture also increases the intermolecular forces, and they affect the frictional forces between solids $[3 ; 12 ; 20]$.

Sliding bodies sliding on a sliding plane with a PVC surface $(R a=0.074 \mu \mathrm{m})$ tend to significantly decrease the coefficient of sliding friction from 0.43 at $30 \%$ humidity to 0.31 at $60 \%$ humidity. In the case of a PVC sliding plane, it can be assumed that there is a significant effect of static electricity on the sliding process. Dielectric materials (PVC and slide body) are known to electrify when in contact with each other. As the relative humidity of the air increases, static electricity from the friction surfaces flows much more intensively, from the graph it can be seen that at a relative humidity of $60 \%$ the coefficient of sliding friction is 0.31 .

Figure 5 shows the experimentally obtained data on the dependence of the values of the static friction coeffsicients $\mu_{s}$ on the roughness $R a$.

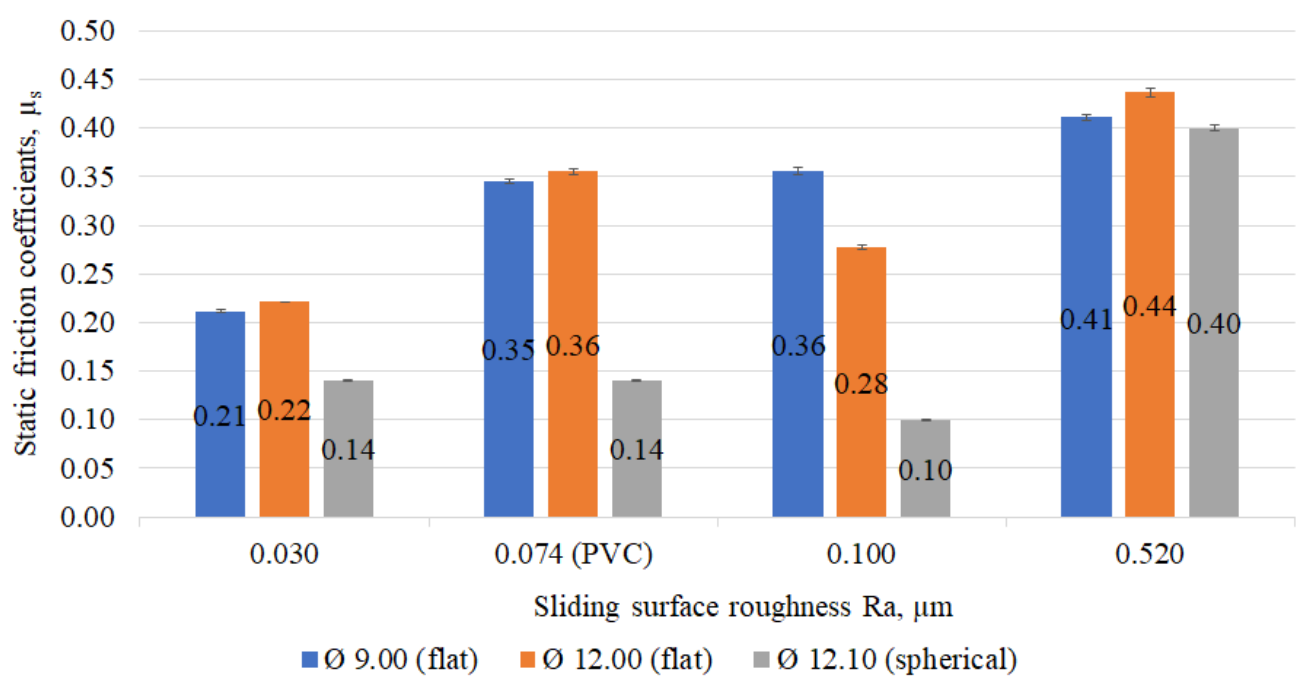

Fig. 5. Dependence of static friction coefficient $\mu_{s}$ on sliding plane roughness $R \boldsymbol{a}$ for each type of sliding bodies

According to the obtained data of the static friction coefficient for the shapes of flat and spherical sliding bodies, it is possible to see the increase of the static friction coefficient $\mu_{s}$ with the increase of the value of the roughness $R a$ of the sliding plane. In all cases for stainless steel sliding planes, the absolute increase of the static friction coefficient is $0.20-0.22$, the coefficient increases are almost proportional to the roughness of the sliding plane. The increase of the static friction coefficient with the increase of the roughness can be explained by the increase of the depth $R z$ values of the individual microroughness and the interaction with the body when they are at rest.

\section{Conclusions}

1. The presence of the initial unstable sliding effect of the sliding bodies on the surfaces of the sliding planes with the smallest roughness has been experimentally determined. They have a significant effect on the reduction of the static angle of the sliding plane and the static friction coefficient as the roughness decreases.

2. The values of the coefficient of sliding friction increase with the decrease of the roughness of the sliding plane material from 0.100 to $0.030 \mu \mathrm{m}$. This effect is related to the relationship between the roughness of the bodies and the materials of the sliding planes, which affects the value of the actual contact area.

3. As the relative humidity of the room increased, the increase of the static friction $\mu_{s}$ and sliding friction $\mu_{\text {slide }}$ coefficients for steel sliding planes was experimentally determined, which is related 
to the increase of condensation meniscus in the microcontact zone of interacting surfaces due to capillary forces (Van der Waals).

4. In the case of the PVC dielectric sliding plane, the effect of humidity increases on the values of the coefficients of the static friction $\mu_{s}$ and the sliding friction $\mu_{\text {slide }}$ is smaller, because the increase of humidity reduces the effect of static electricity.

5. From the obtained data of static and sliding friction coefficients it can be concluded that in order to achieve even and laminar sliding of flat and spherical sliding bodies, it is recommended to use steel surfaces with the roughness value $R a=0.100 \mu \mathrm{m}$, it ensures the lowest dependence of the sliding body sliding rate on the body shape.

\section{References}

[1] Иванович В. Е. “Трибологические исследования взаимодействия листьев табака с рабочими органами машин, (Tribological research on interaction of tobacco leaves with the working bodies of machines)" Научный журнал КубГАУ, №100(06), 2014. (In Russian).

[2] Lu J., "The Influence of Tangential Relative Velocity on Interface Friction in Vibration State," IOP Conf. Ser. Earth Environ. Sci., vol. 237, no. 3, Mar. 2019, p. 5, DOI: 10.1088/17551315/237/3/032100.

[3] Zhang N., Li C. C., Lu A., Chen X., Liu D., Zhu E. "Experimental Studies on the Basic Friction Angle of Planar Rock Surfaces by Tilt Test," J. Test. Eval., vol. 47, no. 1, Jan. 2019, p. 20170308, DOI: 10.1520/JTE20170308.

[4] Гомзяков Н. Д. “О влиянии скорости и числа соударений семян ели обыкновенной на их травмирование, энергию прорастания и всхожесть, (Effect of speed and number of collisions on spruce seeds their injury, vigor and germination)" ИЗВЕСТИЯ САНКТ-ПЕТЕРБУРГСКОЙ ЛЕСОТЕХНИЧЕСКОЙ АКАДЕМИИ, nо. 181, 2007, pp. 66-72. (In Russian)

[5] Chen S., Li S., Yang M. "Sticking/rebound criterion for collisions of small adhesive particles: Effects of impact parameter and particle size," Powder Technol., vol. 274, Apr. 2015, pp. 431-440, DOI: 10.1016/j.powtec.2015.01.051.

[6] Albion K., Briens L., Briens C., Berruti F. "Detection of the breakage of pharmaceutical tablets in pneumatic transport," Int. J. Pharm., vol. 322, no. 1-2, pp. 119-129, Sep. 2006, DOI: 10.1016/j.ijpharm.2006.05.039.

[7] Kalman H. "Attrition control by pneumatic conveying," Powder Technol., vol. 104, no. 3, Oct. 1999, pp. 214-220, DOI: 10.1016/S0032-5910(99)00097-2.

[8] Kalman H. "Attrition of powders and granules at various bends during pneumatic conveying," Powder Technol., vol. 112, no. 3, pp. 244-250, Oct. 2000, DOI: 10.1016/S0032-5910(00)00298-9.

[9] Shen G. Handbook of Friction-Vibration Interactions. United Kingdom: Woodhead Publishing, 2014.

[10] Лужнов В. Д. А. Ю.М. Основы триботехники (Basics of tribotechnics). Москва, 2013. (In Russian)

[11] Blau P. J. "The significance and use of the friction coefficient," Tribol. Int., vol. 34, no. 9, pp. 585591, Sep. 2001, DOI: 10.1016/S0301-679X(01)00050-0.

[12] Wójcik A., Frączek J., Niemczewska-Wójcik M. "The relationship between static and kinetic friction for plant granular materials," Powder Technol., vol. 361, Feb. 2020, pp. 739-747, DOI: 10.1016/j.powtec.2019.11.048.

[13] Fuller D. D. Theory and practice of Llubrication for engineers, 2nd Editio. 1984.

[14] Żurowski W., Zepchło J., Kanaška D., Rucki M. "Concept and assessment of the novel design of tribological tester," Measurement, vol. 170, Jan. 2021, p. 108724,

DOI: $10.1016 /$ j.measurement.2020.108724.

[15] Townsend B. "Static and Kinetic Friction," vol. 2010, no. October 3, 2002, p. 6.

[16] Mate C. M. Carpick R. W. Tribology on the small scale. Oxford: Oxford University Press Inc., New York, 2008.

[17] Arhipova I., Bāliņa S. Statistika ekonomikā. Risinājumi ar SPSS un Microsoft Excel: mācību līdzeklis (Statistics in economics. Solutions with SPSS and Microsoft Excel: a learning tool). Datorzinību centrs, 2003. (In Latvian).

[18] Попов В. Л. Механика контактного взаимодействия и физика трения. (Contact mechanics and physics of friction). Москва: Физматлит, 2013. (In Russian). 
[19] Керопян П. М. В. А.М., Мостаков Р. К. Б. В.А. “Зависимость коэффициента трения в зоне контакта системы колесо - рельс от шероховатости взаимодействующих поверхностей, (Dependence of the coefficient of friction in the contact zone of the wheel - rail system on the roughness of the interacting surfaces)" Горный информационно-аналитический бюллетень., nо. 11, 2016, pp. 80-89 (In Russian).

[20] Crassous J., Bocquet L., Ciliberto S., Laroche C. "Humidity effect on static aging of dry friction," Europhys. Lett., vol. 47, no. 5, Sep. 2017, pp. 562-567, DOI: 10.1209/ep1/11999-00426-2. 